\title{
SYSTEM DYNAMICS APPROACH FOR EVALUATING EXISTING AND FUTURE WATER ALLOCATION PLANNING AMONG CONFLICTING USERS
}

\author{
O. T. Amoo ${ }^{1, *}$, M.D.V. Nakin ${ }^{2}$, A. Abayomi ${ }^{3}$, H. O. Ojugbele ${ }^{4}$, A. W. Salami ${ }^{5}$ \\ ${ }^{1,2}$ Risk and Vulnerability Science Centre, Walter Sisulu University, Eastern Cape, South Africa - ejire36@gmail.com \\ ${ }^{3}$ Dept. of Information and Communication Technology, Mangosuthu University of Technology, Durban. South Africa - \\ taofeekab@yahoo.com \\ ${ }^{4}$ Regional and Local Economic Development Initiative, Graduate School of Business and Leadership, University of KwaZulu-Natal, \\ South Africa - bode228@gmail.com \\ ${ }^{5}$ Dept. of Water Resources and Environmental Engineering, University of Ilorin, Ilorin. Nigeria - awsalami2009@ gmail.com
}

KEY WORDS: System Dynamics, Water Allocation, Climate Change, Sustainable Development, Dependable Flow, Scenarios

\begin{abstract}
:
Water shortages are a chronic and severe problem in South Africa. Allocation of this limited water resources, environmental quality, and policies for sustainable water use are issues of increasing concern that require accurate and timely information to evolve strategies for dynamic natural resources management. Specifically, this paper is aimed to assist the planning, restoring and to rationally allocate the water resources in any river basin in resolving the current water stresses in many parts of South Africa, by using integrated knowledge from simulation and integrated river basin management approach. The developed system dynamic (SD) allocation system was used to investigates the extent to which the framework is 'sustainable' in the medium and long terms in evaluating existing and future water allocation among conflicting users at Mkomazi River Basin (MRB), KwaZulu-Natal Province, South Africa The invented SD framework confirms agricultural water use as the highest demand when compared with other users. The optimal sustainability performance index $(0.25)$ of the system at $70 \%$ dependable flow shows an integrated scenario that combines rainfall variation with improved irrigation water use efficiency as a suitable framework plan. The study uses integrated knowledge from simulation and integrated river basin management approach as a feasible method to assist the planning, restoring and to rationally allocate the water resources in any river basin with similar attributes to the study area in resolving the current water stresses in many parts of the country. Water resources managers would find these tools beneficial in understanding the complex nature of water resources allocation and in determining priorities area which required prompt attention and intervention.
\end{abstract}

\section{INTRODUCTION}

\subsection{Background}

Water has taken a central position in the generation of energy, food production, the sustainability of biodiversity, and global change which call for innovation of management systems for sustainability development. Allocation of freshwater resources between societal needs and natural ecological systems is of great concern for water managers (Cordier, Meinzen, 2017). The problems associated with water resource allocation are closely associated with man anthrophonic activities and natureinduce climate variability (Scheierling, 2011). Human activities have resulted in water pollution. This untreated water is used for drinking, bathing, and washing, thereby causing serious human infections and illnesses, while the combined effect of extreme climate has resulted in excessive heat waves, heavy rainfall, flooding, and wildfire occurrence casualty. Thus, turning these concerns into opportunities requires the need for both water technology innovation and water behavioural change, to manage freshwater sustainably. This development has challenged decision-makers regarding how to reasonably allocate available water resources to meet the competing demands.

The most popular water allocation approach is the priority driven based and equity supplies based approach to domestic, irrigation and ecosystem demand (Weragala, 2010), (Wescoat, 2013) and (Wang, Huang, 2014). Both methods contribute to improve gross domestic product (GDP), provide food security, and ensure public and environmental health (Meinzen-Dick, Mendoza, 1996) and (Bergstrom, Randall, 2016). However, the priority quantity based is the most notably administrative technique employed in the developing world. This method allocates water in a preferential order. This has been attributed to several state objectives geared towards greater socioeconomic development, independence and the sustenance of greater public good (Dinar et al., 1997), (Thompson et al., 2001), (Yates et al., 2005b) and (Sutherland et al., 2014).

The variety of objectives associated with public water allocation requires the assignment of priority directives. However, the prioritised public water allocation has been widely critiqued for its inability to ensure efficient water usage. The core reason behind this has been the lack of institutional incentives (Bergstrom, Randall, 2016). Collet et al. (2015) also stated other reasons for its criticism to include: unassertive decision guidelines during inter-sectoral allocations, political undertones, inordinate pricing structure, lack of synergy among sectoral units as well as the scope for rent-seeking amongst employees of the agency.

Considering the economic scarcity of water, the equity-aspect of water allocation is given less attention in comparison to the efficient-aspect. This represents a new transition towards formulating a framework for pricing water and inputs that affect

\footnotetext{
* Corresponding author
} 
water quality (Berbel, Gómez-Limón, 2000) and (Hassanzadeh et al., 2014). Thus, the emerging-accepted criterion for evaluating water allocation policy is economic efficiency (Varughese et al., 2017). This has taken preference over priority driven (Dinar, 1997). This criterion enables the re-allocation of water from low efficient uses to highly efficient uses. When all the water in a river basin is efficiently allocated, the marginal benefit should be equal across all water use sectors. There are examples from the developed world where water allocation based on the principle of economic efficiency has worked successfully (McCaffrey, 2017) and (Rustinsyah, 2019). In addition to economic efficiency, other critical criteria need to be considered in multiple user environments. This includes: equity, predictability, strategic considerations, flexibility, technical feasibility, political and public interests (Carraro, Sgobbi, 2006), (de Lange et al., 2019) and (Van Niekerk et al., 2019). Considering the broad social, economic and environmental context of the 21st century, Tundisi (2018) states the main causes of "water stress, water crisis, and water scarcity" to be alterations in availability and increased demand which are due to global changes in extreme hydrological events or lack of consistent, governability policy actions on water resources sustainability.

According to some specialists, the water crisis in the $21 \mathrm{st}$ century is much more related to management than to a real crisis of scarcity and stress (Hanjra, Ejaz, 2010). Nevertheless, according to other specialists, it is the result of a set of environmental problems aggravated by economic and social development problems (Tundisi, 2008) and (Stave, Birgit, 2018). Somlyody, Varis (2006) maintain that the deepening and complexity of the water crisis are due to real problems of availability and increased demand, and to a sectoral management process that responds to problems without a systematic approach that tries to foresee them.

Tundisi, Takako (2016) accentuate the need for a systematic, integrated, and predictive approach to water management at a level decentralized to the river basin. According to these authors, a consolidated database transformed into a management tool can be one of the most effective forms of confronting the problem of water scarcity, water stress, and deteriorating quality. Many water researchers believe that sustainable development and management must be supported by the carrying capacity of the available water resources in promoting socio-economic growth, reducing poverty and offering added value to the depleted environment (Pegram et al., 2013), (Omer, 2018) and (Di Baldassarre et al., 2019), especially in a river basin where erratic climate variability prompts much evaporation occurrence compared to precipitation (Stott et al., 2016).

The systems dynamics simulation approach resembles a complex phenomenon from a smaller, readily understood interdependent sub-system using feedback and delay processes that allows conservation of energy, time, and funds in deriving maximum net societal benefit (Amoo, 2018) and (Zarghami et al., 2018). They are built from connectors, modifiers, flows, and stocks. System Dynamics applications in water resources have been comprehensively reviewed by different authors (Mirchi et al., 2013), (Gain, Giupponi, 2015), (Sivapalan, 2015), (Stave, Birgit, 2017), (Duran-Encalada et al., 2017) and (Zarghami, et al., 2018). The system dynamics modelling method stems from 'Dynamo' invented by Forrester at MIT in the 1960s (Sterman, 2018).
Among the different existing system, dynamic simulation environment platform includes: STELLA (ISEE Systems 2016) and (Roberts, 2017); POWERSIM (Matondo, 2002) and (Cordier, et al. 2017); GOLDSIM (Smith, 2016); Simile (Neuwirth, 2017) and VENSIM (Ventana Systems Inc 2016). A SD model offers a robust hypothetical level to conventional simulation or optimization models in arriving at a management decision for a problem. It offers a systematic and efficient analysis of relevant information useful to many organisations (Kunc, 2017). The users are shed away from the mathematical rigour inputs. However, these advantages are still not fully employed in water resources (Ahmad, Simonovic, 2005) over conventional optimisation algorithms with oversimplified systems, aside from not indicating how different basic elements such as feedback affect the dynamics of the system in the future (Zomorodian et al., 2018).

\subsection{The Study Area}

The study area is central to sustainable water supply to the Mkomazi region and KwaZulu-Natal Province. Its water resources are already in competition for supply to irrigation, commercial afforestation, tourism, and recreational activities, as well as paper production which exists near the Mkomazi River mouth with little consideration for the immediate communities' survival. The MRB natural assets and cultural values are of immense value to all the riparian users. They have also served as a means of livelihood for subsistence farming and fish production (DWAF 2014). Figure 2 depicts the study area in relation to South Africa Provinces.

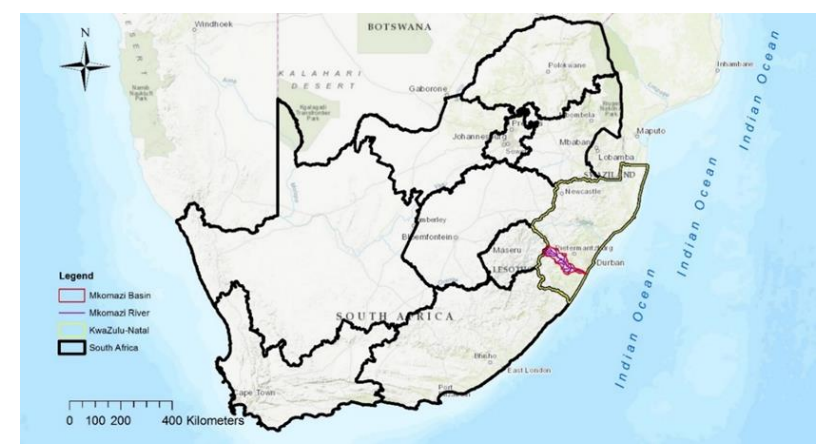

Figure 1. Mkomazi Basin in relation to South Africa

Source: ESRI ArcGIS 10.3.1 Software and online web base map

\section{MATERIALS AND METHODS}

\subsection{Proposed Water System Dynamics Framework}

The proposed developed water trading framework leans on an inclusive simulation of 'Hydrology, Environment, Life (aquatics), Policy and Sensitivity' (HELPS) as a collective response of the basin to efficient water uses with regulation planning which allows movement of water to new users (Amoo, 2018). It uses the socio-hydrological water balance concept which modifies the storage continuity equation (Zhou et al. 2015). Besides defining the relationship between inflow and outflow variables, it considers the water required for ecosystem sustainability. The socio-hydrological water balance framework partitions the evapotranspiration (ET) into societal and ecological systems as defined in (Equation 1 to Equation 5) (Srinivasan et al., 2017) and (Ceola et al., 2016):

$P=E T+R+G+d S / d t$ 


$$
\begin{aligned}
& \mathrm{P}=\mathrm{ET}_{\mathrm{s}}+\mathrm{ET}_{\mathrm{e}}+\mathrm{R}_{\mathrm{out}}+\mathrm{dG} / \mathrm{dt}+\mathrm{dS} / \mathrm{dt} \\
& \mathrm{ET}_{\mathrm{e}}=\mathrm{ET}_{\mathrm{ep}}+\mathrm{ET}_{\mathrm{eR}}+\mathrm{ET}_{\mathrm{eG}} \\
& \mathbf{E T}_{\mathrm{s}}=\mathbf{E T}_{\mathrm{sP}}+\mathbf{E T}_{\mathrm{slR}}+\mathbf{E T}_{\mathrm{sH}}+\mathbf{E T}_{\mathrm{s}, \mathrm{oth}}
\end{aligned}
$$

where

$$
D_{R}+D_{G}=E T_{s I R}+E T_{s H}+E T_{s, o t h}
$$

Where $\mathrm{P}=$ precipitation, $\mathrm{ET}=$ evapotranspiration; $\mathrm{R}=$ surface runoff, $\mathrm{G}=$ groundwater recharge and $d S / d t=$ change in soil water storage. Ecological evapotranspiration component $\left(E T_{\theta}\right)$ includes evapotranspiration from precipitation $E T_{e p}$, surface runoff $\left(E T_{E R}\right)$ and groundwater $E T_{E G}$, in virgin vegetation areas, while, the societal evapotranspiration $\left(E T_{s}\right)$ system component includes evapotranspiration in croplands and grasslands arising from precipitation $\left(E T_{a p}\right)$ and irrigation $\left(E T_{a I}\right)$ and water directly consumed by society: household water $\left(E T_{H}\right)$ and other industries $\left(E T_{\text {oth }}\right)$. Where: water diversions from surface runoff $\left(D_{R}\right)$ and groundwater (DG) represent irrigation water supply to croplands, grasslands, households, and industries. The leftover surface runoff is meant for ecological purposes, $\left(E T_{e R}\right)$ and outflows to the sea $\left(R_{\text {out }}\right)$.

\subsection{Model Development and Simulation}

Before model development, the spatial and temporal scales of the model have to be predetermined, in which water users, basin storage, reservoirs, and downstream ecological zones are defined as unit's user. The time horizon of most socio-economic plans is 25 to 30 years (Ahmed, Simonovic, 2000), and therefore, the planning period for this study has been taken as 30 years, with a time increment of 1 year. Based on the geographical homogeneity, the study area was divided into 7 geographic units which have greatly reduced the temporal and spatial variability, it is still a complex task to simulate large socio-economic sectors and link them together (Xu et.al., 2002). To that end, the hierarchical decomposition technique was used, with each complex sector being disaggregated into different sub-sectors, e.g., the industrial water sector was divided into three subsectors: city, town and rural, due to the significant difference of the characteristics concerning industrial pattern, unit water rate, growth rate, etc.

The mathematical formulations of the major processes of water supply and water demand represented in the model are presented in the Causal Loop Diagram (CLD) and the Stock Flow Diagram (SFD) interface. CLDs are useful qualitative analytical tools for representing relationships among system variables that produce dynamic feedback structure (Sterman, 2000) while the stock and flow mathematical models are created using feedback loops that link the various sub-systems based on the socio-hydrological mass balance. The SFD can be used to illustrates scenarios for a hypothetical water trading market in deriving efficient water allocation among the riparian users. Its iteratively determines water prices for each water user in the context of water priority and market surrogate.

\subsection{Conceptual CLD and SFD development}

Figure 1 depicts the conceptualised CLD while Figure 2 is the SFD representation of the SD framework. The conceptual integrated model presented was developed in close cooperation with the KwaZulu-Natal Province Department of Water and Sanitation's stakeholder staff in Durban. This assisted in a fair representation of the socio-hydrological water-trading configuration. The CLD indicates how a complex web of socioeconomic and environmental challenges confronted by a basin could be managed sustainably, while the SFD relates the various sub-system feedbacks to the socio-hydrological mass balance of the basin. The SD mechanism allows effective evaluation linkage between water for livelihoods and water as a resource. This allows the integration of the three 'Es' - economic, efficiency, and equity - to be employed.

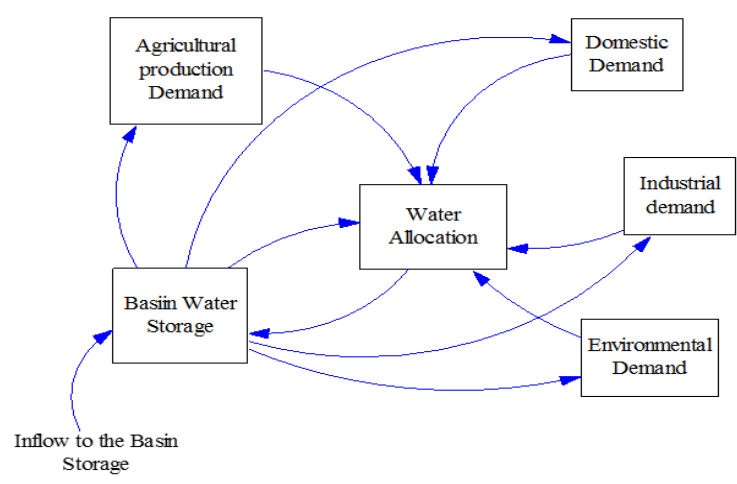

Figure 2. Causal Loop Diagram for the water system model

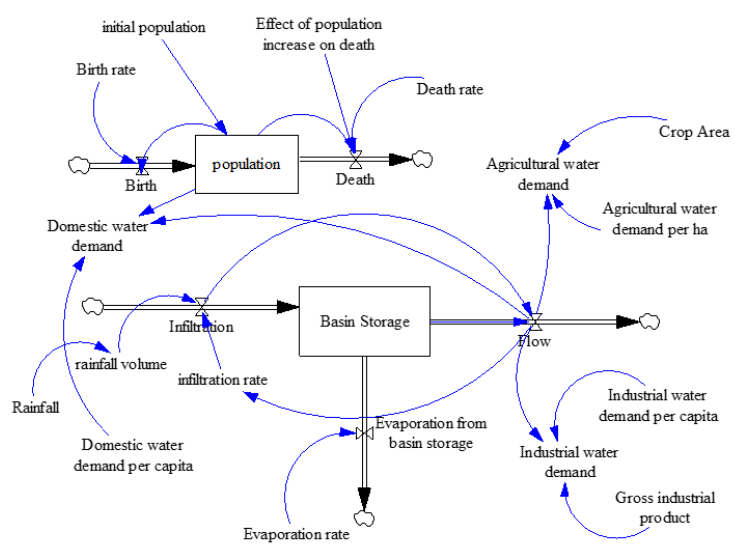

Figure 3. Stock-Flow Diagram of the population sub-sector

\subsection{Performance of Water Resource Systems}

There are many criteria to evaluate the performance of water resource systems such as reliability, vulnerability, and resiliency (Zhang et al., 2017), (Ren et al., 2020) and (Haro-Monteagudo et al., 2020). This study adopted the sustainability index (SI) by (Xu et al., 2002) and (Wang et. al., 2019). SI is defined as the ratio of aggregated possible water deficit relative to the corresponding supply in the same region, as shown in Equation 6:

$$
S I=\left\{\begin{array}{cl}
\frac{(S-D)}{S} & S>D \\
0 & S \leq D
\end{array}\right.
$$


where $\mathrm{D}$ is the water demand, and $\mathrm{S}$ is the available water supply. SI values greater than 0.2 correspond to low or no stress of water supply, which implies that water demand is less than or equal to $80 \%$ of the potential water supply, whereas those smaller than 0.2 reflect vulnerable conditions, i.e., water demand is greater than $80 \%$ of the potential water supply. Values of zero indicate an unsustainable water supply, i. e. water demand already equals or exceeds all available local water resources.

\subsection{Model Simulation and Validation}

SD model's validity was verified in terms of its structural and behavioural aspects. The model was validated by examining its Ability to reproduce historic behavior from 2010 to 2015 . The variables being examined included Total Population, Agricultural Irrigation Area, and Gross Industrial water use; these variables are decisive factors in the model behavioural aspects. The second validation test - extreme condition testing examined the degree to which the model "responded plausibly when subjected to extreme policies, shocks, and parameters" (Sterman, 2000). The model was tested by drastically increasing the key stocks driving demand in the model (like population), and decreasing the key stocks driving water supply in the model.

\begin{tabular}{|c|c|c|}
\hline Variables & Parameters & Source \\
\hline eThekwini medium variant & $3,609,259$ & (Visagie, \\
\hline $\begin{array}{l}\text { Gross industrial product per } \\
\text { annum }\end{array}$ & 101.86 & (DWAF, \\
\hline $\begin{array}{l}\text { Domestic water demand per } \\
\text { capita }\end{array}$ & $135 \mathrm{~m}^{3}$ & $\begin{array}{l}\text { (DWAF, } \\
\text { 2019) }\end{array}$ \\
\hline $\begin{array}{l}\text { Industrial water demand per } \\
\text { capita }\end{array}$ & 44Mm3/annum & $\begin{array}{l}\text { (Ruiters, } \\
\text { Maselagan } \\
\text { ye, 2016) }\end{array}$ \\
\hline $\begin{array}{l}\text { Irrigation water demand per crop } \\
\text { per hectare }\end{array}$ & $475 \mathrm{~m} 3$ & $\begin{array}{l}\text { (DWAF, } \\
\text { 2014) }\end{array}$ \\
\hline $\begin{array}{l}\text { Water demand per cold-blooded } \\
\text { animal (WDCDA) }\end{array}$ & 10L/(capita*day) & $\begin{array}{l}\text { (DWAF, } \\
\text { 2006) }\end{array}$ \\
\hline $\begin{array}{l}\text { Water demand per warm- } \\
\text { blooded animal }\end{array}$ & 45L/(capita*day) & $\begin{array}{l}\text { (DWAF, } \\
\text { 2006) }\end{array}$ \\
\hline (WDWDA) & $5 \%$ & \\
\hline $\begin{array}{l}\text { Seasonal difference in demand } \\
\text { (Ss, and } \mathrm{Si} \text { ) }\end{array}$ & & \\
\hline
\end{tabular}

Table 1. Parameters value used for each of the riparian water demands and supply

\section{RESULTS AND DISCUSSION}

Using the necessary parameters from Table 1 and its utilisation in the theoretical conceptualised SDM framework as depicted in Figures 2 and 3. Figure 4 shows a pictorial plot of the hydrological components' sustainability and the need for increased storage basin with time area. The various water demand sub-sectors will continue to be of high increased compared to the available water in the storage basin. The landuse, and vegetation cover impacts are the most significant impacts occurring in the basin. They have affected the hydrologic cycle, runoff generation mechanisms and the water balance configuration as supported by Loveland et al. (2000).

Thus, necessitating measures for regulating water use. This entails creating awareness to avoid water use wastage in its various uses, crop diversification, and precision water use in farming, the use of metering and pricing for water auditing. The challenges confronting water regulation among the contending different uses and users reveal societal activities of commercial forestry, irrigation, dryland, and subsistence agriculture as it interrupts the basin hydrological runoff and seasonal variability in streamflow. This finding is also collaborated by a study carried out by (Katjavivi, 2009).

\section{Storage basin}

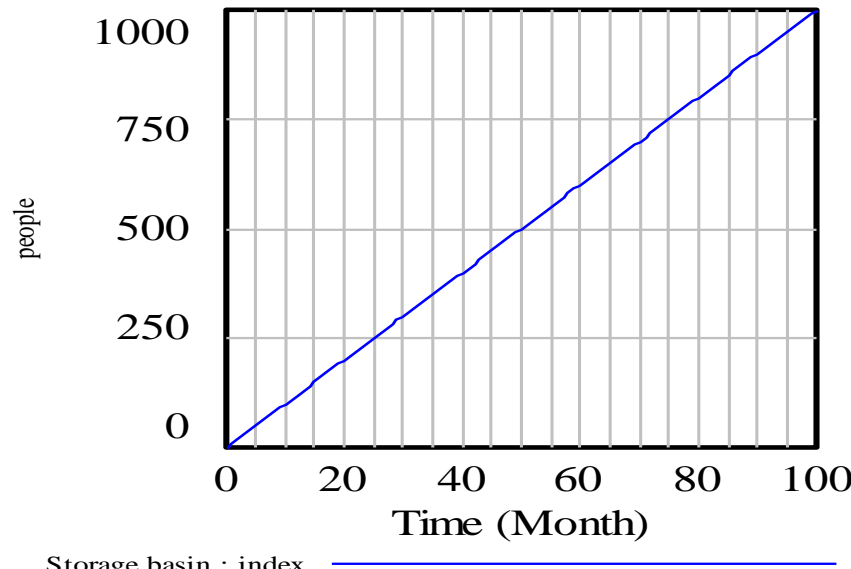

Figure 4: Population and storage basin dynamics variation

Using the sustainability index (SI) defined in Equation 6, the medium and long-term water fulfillment from both sides (supply and demand) at varied dependability flow conditions was as depicted in Table 2 .

\begin{tabular}{|c|l|c|c|c|c|}
\hline Variables & \multicolumn{1}{|c|}{ Scenarios } & Variables & $60 \%$ & $70 \%$ & $80 \%$ \\
\hline A & $\begin{array}{l}\text { Business as } \\
\text { usual (BaU) }\end{array}$ & SI & 1.0 & 0.25 & 0.36 \\
B & $\begin{array}{l}\text { Climate change } \\
\text { (Precipitation } \\
\text { varies in 10\%) }\end{array}$ & SI & 0.75 & 0.24 & 0.30 \\
C & $\begin{array}{l}\text { Irrigation } \\
\text { improvement } \\
\text { Integrated } \\
\text { scenario }\end{array}$ & SI & 0.50 & 0.23 & 0.26 \\
D & 0.25 & 0.20 & 0.22 \\
\hline
\end{tabular}

Table 2. Sustainability index for varied dependable flow conditions

The result of the integrated scenarios $(B+C)($ Table 2$)$ of the SD sustainability index at varied dependability conditions to the basin storage basin does not only predict the likely hydrological dynamics variation at a given time but also reveal the need for increased storage capacity to cater for the growing population.

\section{Sustainability Index}

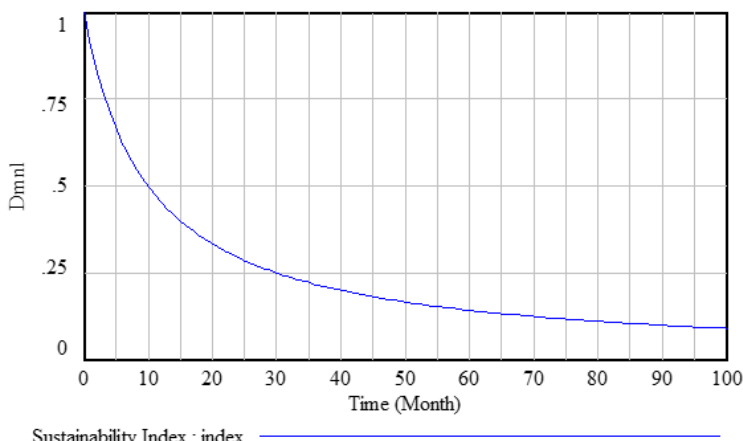

Figure 5. The integrated scenarios sustainability index 
The integrated scenario (D) combines rainfall variation (B) with improved irrigation water use efficiency $(\mathrm{C})$ and gives optimal sustainability performance $(0.25)$ of the system at $70 \%$ dependable flow over a long time. This implies that water demand is less than or equal to $80 \%$ of the potential water supply. Figure 5 discusses the exponential curve of the integrated scenario sustainability.

\section{CONCLUSION AND RECOMMENDATIONS}

In this study, the complex scenarios of the socio-hydrological basin water system were simulated to satisfy long-term socioeconomic plans on a 30 years future time scale. The study explores the socioeconomic and environmental consequences of water regulation in the Mkomazi River Basin (MRB); develop a system dynamic (SD) allocation system and investigate the extent to which the framework is 'sustainable' in the medium and long terms The output results of the system dynamic model show it to be a veritable tool for cause and effect evaluation for a decision support system. It has helped explore a top-bottomtop management approach to give more insight into the successful implementation of integrated watershed management. The SD simulation used in this study can be improved with a more realistic negotiated model if the local water users' associations and water managers' stakeholders can be incorporated in the simulation conceptualisation design. However, the challenges confronting water regulation among the contending different uses and users reveal societal activities of commercial forestry, irrigation, dryland, and subsistence agriculture as it interrupts the basin hydrological runoff and seasonal variability in streamflow.

\section{ACKNOWLEDGEMENTS}

The authors expressed their appreciation to the Department of Water and Sanitation DWS, KwaZulu-Natal, South Africa who supported this research with logistic data.

\section{REFERENCES}

Ahmad, S., Slobodan, P.S., 2000: System dynamics modeling of reservoir operations for flood management. Journal of Computing in Civil Engineering 14, no. 3 (2000): 190-198.

Amoo, O.T., 2018: Integrated hydrological modelling for sustainable water allocation planning: Mkomazi Basin, South Africa case study. Ph.D. dissertation.

Berbel, J., Gómez-Limón, J. A., 2000: The impact of waterpricing policy in Spain: an analysis of three irrigated areas. Agricultural Water Management, 43 (2): 219-238.

Bergstrom, J.C., Randall, A., 2016: Resource economics: an economic approach to natural resource and environmental policy. Edward Elgar Publishing.

Ceola, S., Alberto, M., Tobias K., Fiona, D., Heidi, K., Ida W., Gemma Carr, et al., 2016: Adaptation of water resources systems to changing society and environment: a statement by the International Association of Hydrological Sciences. Hydrological Sciences Journal 61, no.16, 2803-2817.

Collet, L., Ruelland, D., Estupina, V. B., Dezetter, A., Servat, E., 2015: Water supply sustainability and adaptation strategies under anthropogenic and climatic changes of a meso-scale Mediterranean catchment. Science of the total environment, 536: 589-602.
Cordier, M.T.U., Bertrand, H., 2017: An input-output economic model integrated within a system dynamics ecological model: Feedback loop methodology applied to fish nursery restoration. Ecological Economics 140, 46-57.

de Lange, J., Molaolwa, Y.L., Kotzé, J., van der Merwe, L., Esterhuizen, A.M., 2019: Training Manual for Groundwater Resource Management and Groundwater Governance for Municipalities in South Africa.

Di Baldassarre, G., Murugesu, S., Maria Rusca, C.C., Margaret Garcia, H.K., Megan Konar, et al., 2019: Sociohydrology: Scientific challenges in addressing the sustainable development goals. Water Resources Research 55, no. 8, 6327-6355.

Dinar, A., Rosegrant, M.W., Meinzen-Dick, R. S., 1997: Water allocation mechanisms: principles and examples. World Bank Publications.

Duran-Encalada, Jorge A.A., Paucar-Caceres, E.R., Bandala, G.H., 2017: The impact of global climate change on water quantity and quality: A system dynamics approach to the USMexican transborder region. European Journal of Operational Research 256, no. 2, 567-581.

DWAF, 2014: Department of Water Affairs and Forestry (DWAF). Volume 3., 2014: Eco-classification And Ewr Assessment on the Mkomazi, Umngeni, and Mvoti Rivers. 7. Kwazulu-Natal Province: Dwaf. Gov. Za 7 Gazette.

DWAF, 1996: Department of Water Affairs and Forestry (DWAF). South African Water Quality Guidelines (first edition). Volume 8: Field Guide.

Hanjra, M.A., Ejaz, Q., 2010: Global water crisis and future food security in an era of climate change. Food Policy 35, no. 5 365-377.

Haro-Monteagudo, D., Leticia P., Santiago B., 2020: Long-term Sustainability of Large Water Resource Systems under Climate Change: a Cascade Modeling Approach. Journal of Hydrology, 124546.

Hassanzadeh, E., Elshorbagy, A., Wheater, H., Gober, P., 2014: Managing water in complex systems: An integrated water resources model for Saskatchewan, Canada. Environmental Modelling \& Software, 58: 12-26.

Hussien, M.I., Rasha A.A., 2017: System Dynamics Modeling and Simulation for E-Banking: The Egyptian Context. IBIMA Business Review 2017.

Katjavivi, P., 2009: SADC Small states of southern Africa and remittances, Small States Forum. World Bank, Istanbul,

Kunc, Martin, ed. 2017: System dynamics: soft and hard operational research. Springer.

Loveland, T.R., Reed, B.C., Brown, J.F., Ohlen, D.O., Zhu, Z., Yang, L., Merchant, J.W., 2000: Development of a global land cover characteristics database and IGBP DISCover from $1 \mathrm{~km}$ AVHRR data. International Journal of Remote Sensing, 21 (67): 1303-1330.

McCaffrey, S.C., John S.M., Melvin W., 2017: Challenges to Water Rights: Uses and Benefits, Dominance, and Inequality. In Promoting Equity, Cooperation, and Innovation in the Fields of 
Transboundary Waters and Natural Resources Management, pp. 189-250. Brill Nijhoff.

Meinzen-Dick, R., Mendoza, M., 1996: Alternative water allocation mechanisms: Indian and international experiences. Economic and Political Weekly: A25-A30.

Meissner, R., Maronel S., Jacobs-Mata, I., Moyo, E., Shadung, J., Nohayi, N., Mngadi, T., 2019: The Perceived State of Water Security in the Sekhukhune District Municipality and the eThekwini Metropolitan Municipality. In Understanding Water Security at Local Government Level in South Africa, pp. 73134. Palgrave Pivot, Cham.

Nelliyat, P., 2017: Bio-resources valuation for ensuring equity in access and benefit-sharing: issues and challenges. In Biodiversity for Sustainable Development, pp. 135-153. Springer, Cham.

Neuwirth, C., 2017: System dynamics simulations for dataintensive applications. Environmental modelling \& software 96 ,140-145.

Omer, A.M., 2018: Sustainability Criteria for Water Resource Systems: Sustainable Development and Management. Int. J. Adv. Res. Water Resc. Hydr. Engi 1, no. 1\&2 (2018): 1-19.

Ren, K., Shengzhi, H., Qiang, H., Hao, W., Guoyong, L., Wei, F., Pei, L.,2020: Assessing the reliability, resilience, and vulnerability of water supply system under multiple uncertain sources. Journal of Cleaner Production 252 (2020): 119806.

Roberts, S.D., Dennis, P., 2017: The history of simulation modeling. In 2017 Winter Simulation Conference (WSC), pp. 308-323. IEEE, 2017.

Rustinsyah, R., 2019: "Determining the satisfaction level of water user association service quality for supporting sustainable rural development." Development Studies Research 6, no. 1 (2019): 118-128.

Ruiters, C., Maselaganye, P.M., 2016: Public-private partnership conceptual framework and models for the funding and financing of water services infrastructure in municipalities from selected provinces in South Africa. Water Sa 42, no. 2. 291-305.

Scheierling, S.M., 2011: Assessing the direct economic effects of reallocating irrigation water to alternative uses: concepts and an application. The World Bank.

Somlyódy, L., Olli V., 2006: Freshwater under pressure. International Review for Environmental Strategies 6, no. 2. 181-204.

Sutherland, C., Hordijk, M., Lewis, B., Meyer, C., Buthelezi, S., 2014: Water and sanitation provision in eThekwini Municipality: a spatially differentiated approach. Environment and Urbanization: 0956247814544871.

Stott, P.A., Nikolaos C., Friederike, EL. O., Ying S., Jean-Paul V., Geert Jan van, O,, Robert V., et al., 2016: Attribution of extreme weather and climate-related events. Wiley Interdisciplinary Reviews: Climate Change 7, no. 1 (2016): 2341 .
Stave, K., Birgit, K., 2017: System dynamics as a framework for understanding human-environment dynamics. In Social and ecological system dynamics, pp. 25-36. Springer, Cham.

Sterman, J. 2018: System dynamics at sixty: the path forward. System Dynamics Review 34, no. 1-2 (2018): 5-47.

Smith, F., 2016: User Guide for GoldSim Model to Calculate PA/CA Doses and Limits. No. SRNL-STI--2016-00530. Savannah River Site (SRS),

Srinivasan, V. M., Sanderson, M.G., Megan Konar, G. B., Murugesu, S., 2017: Prediction in a socio-hydrological world. Hydrological Sciences Journal 62, no. 3: 338-345.

Thakur, R., Geoffrey Harris, S.T., Stanley, O., 2019: Factors contributing towards high water usage within poor communities in KwaZulu-Natal, South Africa. WIT Transactions on Ecology and the Environment, 239, 1-10.

Thompson, H., Stimie, C., Richters, E. Perret, S., 2001: Policies, legislation and organizations related to water in South Africa, with special reference to the Olifants river basin. IWMI.

Tundisi, J.G., 2008: Water resources in the future: problems and solutions. estudos avançados 22 , no. 63. 7-16.

Tundisi, J.G., Takako, M.T., 2016: Integrating ecohydrology, water management, and watershed economy: Case studies from Brazil. Ecohydrology \& Hydrobiology 16, no. 2, 83-91.

Van Niekerk, J.B., David, G.A., Susan Taljaard, S.P., Weerts, D.L., Colin T., Pieter, V.R., 2019: Assessing and planning future estuarine resource use: A scenario-based regional-scale freshwater allocation approach. Science of the Total Environment 657, 1000-1013.

Varughese, S., Devi Prasad, K.V., 2017: Water trading opportunities and irrigation technology choice: An example from south India. Water resources and rural development 9,39 45 .

Visagie, J., 2019: Measuring regional labour markets in South Africa: How robust are sub-national estimates from the Quarterly Labour Force Survey? Development Southern Africa 36 , no. 4, 461-475.

Wang, S., Huang, G.H., 2014; An integrated approach for water resources decision making under interactive and compound uncertainties. Omega, 44: 32-40.

Wang, K., Evan, G.R, Junguo L. D., 2019: Integrated water resources management and modeling: A case study of Bow river basin, Canada. Journal of Cleaner Production 240, 118242 .

Weragala, D.K., 2010: Water allocation challenges in rural river basins: A case study from the Walawe River Basin, Sri Lanka. All Graduate Theses and Dissertations: 589.

Wescoat, J.J., 2013: Reconstructing the duty of water: a study of emergent norms in socio-hydrology. Hydrology and Earth System Sciences, 17 (12): 4759.

Xu, Z.X., Takeuchi, H.I., Zhang, X.W., 2002: Sustainability analysis for Yellow River water resources using the system 
dynamics approach. Water Resources Management 16, no.3, 239-261.

Yates, D., Purkey, D., Sieber, J., Huber-Lee, A., Galbraith, H. 2005a. WEAP21: A demand-priority-and preference-driven water planning model: Part 2: Aiding freshwater ecosystem service evaluation. Water International, 30 (4): 501-512.

Yates, D., Sieber, J., Purkey, D., Huber-Lee, A., 2005b: WEAP21: A demand-, priority-, and preference-driven water planning model: part 1: model characteristics. Water International, 30 (4): 487-500.

Zarghami, S., Ashkan, I.G., Frank, S., 2018: System dynamics modelling process in water sector: a review of research literature. Systems Research and Behavioral Science 35, no. 6: 776-790.

Zhang, C., Bo Xu, Y.L., Guangtao, F., 2017: Exploring the relationships among reliability, resilience, and vulnerability of water supply using many-objective analysis. Journal of water resources planning and management 143, no.8, 04017044.

Zomorodian, M., Sai Hin Lai, M.H., Shaliza Ibrahim, S.E., Fatemi., A.E., 208: The state-of-the-art system dynamics application in integrated water resources modeling. Journal of environmental management 227 294-304. 